\title{
Comorbidities of patients with chronic obstructive pulmonary disease (COPD): thyroid abnormalities in stable COPD
}

\section{Corresponding author:}

Daniela Buklioska llievska, "Nikola Parapunov" 31/1-3 Skopje, Macedonia, e-mail: dbuklioska@yahoo.com
Medical Research Journal 2021; Volume 6, Number 3, 204-210 10.5603/MRJ.a2021.0040 Copyright (C) 2021 Via Medica ISSN 2451-2591 e-ISSN 2451-4101

\begin{abstract}
Objective: The aim of the study is to evaluate the prevalence of thyroid abnormalities in patients with stable chronic obstructive pulmonary disease (COPD) and the relationship between thyroid disorder and ventilatory function tests and arterial blood gas analyses.

Material and methods: This cross-sectional study was conducted with 60 patients with stable COPD without diagnosed thyroid disorder before the study (37 males and 23 females aged 40-75) as the Investigated Group (IG) and 30 subjects from the general population without COPD as the Control Group (CG). They were matched by age, gender and body mass index with the IG. All patients underwent laboratory tests, thyroid hormones -free thyroxin (fT4), thyroid-stimulating hormone (TSH), and free triiodothyronine (fT3), pulmonary function tests $\left(\mathrm{FEV}_{1}, \mathrm{FVC} \%, \mathrm{FEV}_{1} / \mathrm{FVC}\right.$, FEF25-75\%), and $\mathrm{ABG}$ parameters $\left(\mathrm{PH}, \mathrm{PaCO}_{2}, \mathrm{PaO}_{2}\right.$, $\mathrm{HCO}_{3}, \mathrm{O}_{2}$ saturation). The severity level in patients with COPD was determined according to GOLD (Global Initiative for Chronic Obstructive Lung Disease) criteria and classified into four stages GOLD I, II, III, and IV. Results: Our results presented a statistically significant difference between prevalence of thyroid hormones abnormalities in stable COPD compared to controls 18 (30.0\%) vs $3(10.0 \%), p=0.0355 ; p<0.05)$. Thyroid dysfunction among COPD patients was more common in females than males. Serum level of TSH was lower than the normal range in 18 patients (30.0\%) from the IG and in $3(10.0 \%)$ from the CG, with a statistically significant difference, $p=0.0355 ; p<0.05$. Thyrotoxicosis with low serum TSH and a higher serum level of $\mathrm{fT} 3$, according to the referent range, was present in 8 patients (13.3\%), and in no patients from the $C G 0(0.0 \%), p=0.0375 ; p<0.05$. The prevalence of subclinical hyperthyroidism with low serum TSH and normal serum level of fT3 was higher in the IG -10 patients $(16.7 \%)$ compared with 3 (10.0\%) of the CG, but the difference was not statistically significant $p=0.3970$. Acute exacerbation frequency of $I G$ was significantly higher than in the $C G(1.6 \pm 0.42$ and $0.82 \pm 0.79$ respectively; $p<0.0001)$. A positive significant relationship between acute exacerbation frequency and TSH values was found ( $P$ $<0.0001 ; r=0.82$ ). The mean values of $\mathrm{fT} 3$ in the IG were significantly increasing with the increased severity of COPD. The degree of airflow limitation in COPD ( $\mathrm{FEV}_{1}$ as a percentage of the predicted value, FEV ${ }_{1} \%$ pred) was significantly negatively correlated to $\mathrm{fT} 3$, Pearson correlation, $(R=-0.525 ; p=0.000$; $p<0.01)$. FEV $V_{1} \%$ pred was positively correlated with $T S H(R=0.358 ; p=0.005 ; p<0.01)$. Significant negative correlations were present between fT3 levels and both $\mathrm{PaO}_{2}$ and $\mathrm{SO}_{2}$ in the IG, and elevation of fT3 was associated with higher $\mathrm{PaCO} 2$.

Conclusion: The present study confirms that both clinical and subclinical hyperthyroidism was higher in patients with COPD compared to the non-COPD group. TSH and fT3 are related to lung function. A better understanding of the correlation between thyroid gland disorders and COPD may contribute to better care of patients.
\end{abstract}

Key words: COPD, comorbidity, thyroid gland, thyroid hormone, hyperthyroidism

Med Res J 2021; 6 (3): 204-210 


\section{Introduction}

Chronic obstructive pulmonary disease (COPD) is a common, preventable, and treatable chronic airway inflammatory disease. COPD has been the third leading cause of death in the world since 2020. COPD is a respiratory disease with systemic complications, which is characterized by chronic airflow limitation due to the destruction of lung parenchyma and airways. It is a multicomponent disease with extrapulmonary effects, such as cardiovascular disease, anemia, polycythemia, malnutrition, muscle disorder, osteoporosis, metabolic syndrome, diabetes, gastroesophageal reflux, anxiety, depression, hormonal imbalance, infections, lung cancer, and thrombosis. Many systems including the endocrine system are affected by COPD. Comorbidities not only affect symptom burden, health status, and quality of life, but they also carry the risk of hospitalization and mortality in patients with COPD [1_5]. Some comorbidities, such as coronary artery disease or metabolic syndrome are well-recognized in COPD patients. But thyroid diseases, which are more common in COPD patients compared to patients who do not have COPD, are underestimated despite important clinical consequences [6]. Abnormalities in thyroid hormone regulation are encountered frequently in nonthyroidal diseases; these include normal or decreased total and free thyroxine (TT4 and FT4, respectively), decreased total (TT3) and free (FT3) triiodothyronine, along with usually normal thyroid-stimulating hormone (TSH) levels [7]. Neurohormones, blood gas abnormalities, glucocorticoid administration also disturb the hormonal balance [8]. Hypoxia and hypercapnia cause destruction in sella turcica and pituitary gland dysfunction. During the course of COPD with hypoxia, peripheral metabolism of thyroid function changes, and thyroid hormone levels decrease in patients with very severe COPD [9]. Frequently drugs used by COPD patients to treat comorbidities, such as amiodarone, may be a cause of thyroid disorder [10]. Systemic inflammation may express the link between COPD and thyroid diseases. Supporting this, Karadag et al. [11] found a positive correlation between interleukin 6 , which is a systemic inflammation marker, and total triiodotironine (TT3) and TT3/TT4 (total tyhroxine) in patients with stable COPD [11]. Smoking increases systemic inflammation independently from associating COPD and may affect thyroid functions [12]. Higher levels of serum total triiodothyronine (TT3) were found in young healthy smokers compared to non-smoking control subjects, which may suggest that smoking acts independently of coexistent diagnosis of COPD [13]. On the other hand, hormones may affect regulation of breathing. Some hormones act on the level of the central nervous system, some have an impact on peripheral chemoreceptors, others may contribute to this process by influencing the metabolism rate, and others exert their effect directly on receptors in the respiratory tract. Hypothyroidism may also cause alveolar hypoventilation, decreased lung volumes, upper airway obstruction, depression in respiratory stimulus and respiratory failure [14]. A cross-sectional study from Spain showed that patients with COPD had a higher prevalence of thyroid disease (14.2\%) than the expected standardized prevalence of chronic diseases $(11.06 \%)$, and the prevalence of thyroid disease was higher in female than male patients (24.6\% vs $10.9 \%)$ [15]. Gumus et al. [16] found a decrease in triiodothyronine $\left(\mathrm{T}_{3} ; 18.2 \%\right)$ and thyroid-stimulating hormone (TSH; 30.3\%) in patients with exacerbation of COPD. The exacerbation frequency was higher in patients with COPD with hypothyroidism than in those without hypothyroidism. The frequency of COPD exacerbation was positively correlated with TSH levels [16].

The objective of the study is to evaluate the prevalence of thyroid abnormalities in patients with stable COPD and the relationship between thyroid disorder and ventilatory function tests and arterial blood gas analyses.

\section{Material and methods}

\section{Study design and setting}

A cross-sectional study aimed to evaluate the prevalence of thyroid abnormalities in patients with stable COPD and the relationship between thyroid disorder and ventilatory function tests and arterial blood gas analyses was performed at the City General Hospital "8mi Septemvri", Skopje.

\section{Study subjects}

The study population included 60 patients with stable COPD (37 males, 23 females), diagnosed according to the actual Global Initiative for Chronic Obstructive Lung Disease (GOLD) criteria and 30 subjects without COPD matched to the COPD group by sex, age, body mass index (BMI), and smoking status. All enrolled subjects gave their written informed consent before entering the study.

\section{Inclusion criteria for Investigated Group (IG)}

Both sexes, aged 40-75 years, with diagnosed COPD according to the actual GOLD criteria, had a history of current or former smoking (equal or more than 10 pack-years) and were clinically stable condition at least 6 weeks prior to involvement. 


\section{Exclusion criteria for Investigated Group (IG)}

The exclusion criteria were age less than 40 years and more than 75 years, other chronic respiratory diseases (asthma, bronchiectasis, active tuberculosis, sarcoidosis, lung carcinoma, pulmonary fibrosis, sleep apnea syndrome), BMI $>35 \mathrm{~kg} / \mathrm{m}^{2}$, electrolyte imbalance, hepatic, renal failure, anemia. We excluded patients with immunosuppressive therapy, patients during acute exacerbation of COPD, and those who received systemic corticosteroids, medications containing iodine, amiadorone and/or contrast material within the prior two months, those who could not perform the pulmonary function tests, those with thyroid surgery, other endocrine diseases (including diabetes mellitus), neuromuscular and cardiovascular diseases, symptoms of any infections or using anti-inflammatory medications. Patients who did not agree to participate were excluded from the study.

\section{Inclusion criteria for the Control Group (CG)}

We included patients aged from 40 to 75 years, with a smoking history $\geq 10$ pack-years, current or former smokers, patients with normal spirometry, in stable clinical condition, without significant difference in sex, age, $\mathrm{BMI}$, and patients who signed consent for participation.

\section{Methods}

All patients underwent laboratory testing and pulmonary function tests. The severity level in patients with COPD was determined according to GOLD criteria.

The BMI as a measure of body fat, based on height and weight that applies to the adult population, was determined in all study subjects by computed calculation using a BMI calculator [17].

Classification of smoking status was done as per the World Health Organization (WHO) recommendations by the Brinkman Index, as a clinical quantification of cigarette smoking is used to measure a person's exposure to tobacco, and it is calculated as number of pack-years $=$ (number of cigarettes smoked per day / 20) $\times$ number of years smoked [17].

\section{Pulmonary evaluation}

The pulmonary evaluation included: dyspnea severity assessment, baseline, and post-bronchodilator spirometry, arterial gas analysis, and chest X-ray (to exclude respiratory disease other than COPD).

The baseline spirometry, including measures of forced vital capacity (FVC), forced expiratory volume in one second $\left(\mathrm{FEV}_{1}\right), \mathrm{FEV}_{1} / \mathrm{FVC}$, and maximal expiratory flow at $75 \%, 50 \%, 25 \%$, and $25-75 \%$ of $F V C\left(M F_{75}\right.$,
$\mathrm{MEF}_{50}, \mathrm{MEF}_{25}$, and $\mathrm{MEF}_{25-75}$, respectively), was performed in all subjects using electronic spirometer Spirobank G USB Spirometer (Medical International Research, Roma, Italy) - the best result from three measurements the values of $\mathrm{FEV}_{1}$ were recorded. The difference between two spirometry values of FEV1 was less than $5 \%$. The results of spirometry were expressed as percentages of the predicted values, according to the actual recommendations of the European Respiratory Society and American Thoracic Society [18]. Bronchodilator test was performed by spirometric measurements before and 20 minutes after administration of $400 \mathrm{mg}$ salbutamol by metered-dose inhaler through a spacer. The post-bronchodilator value of the $\mathrm{FEV}_{1} / \mathrm{FVC}$ ratio was less than 0.70 and indicated persistent airflow limitation [18]. According to the actual GOLD recommendations, COPD was considered by finding of a post-bronchodilator $\mathrm{FEV}_{1} / \mathrm{FVC}$ ratio less than 0.70 in symptomatic subjects (dyspnea, chronic cough, and/or sputum production) with a history of exposure to risk factors for the disease (noxious particles and gases). In addition, according to the $\mathrm{FEV}_{1}$ value, airflow limitation in the subjects with COPD, i.e. severity of the disease, was classified as mild $\left(\mathrm{FEV}_{1}\right.$ value higher than $80 \%$ of the predicted value), moderate (FEV 1 value higher than $50 \%$ but lower than $80 \%$ of the predicted value), severe $\left(\mathrm{FEV}_{1}\right.$ value higher than $30 \%$ but lower than $50 \%$ of the predicted value), and very severe ( $\mathrm{FEV}_{1}$ value lower than $30 \%$ of the predicted value [1]). Gas analysis was performed with SIEMENS RAPIDPOINT 405 System (Siemens Healthineers, Australia).

\section{Laboratory evaluation}

Analysis of venous blood was taken in the morning at 8 a.m (following an overnight fast) and biochemistry, sedimentation rate, C-reactive protein, thyroid hormones were analyzed. Thyroid-stimulating hormone (TSH) (normal range: $0.35-4.0 \mathrm{mlU} / \mathrm{L}$ ), free triiodothyronine (fT3) (normal range: $2.3-6.7 \mathrm{pmol} / \mathrm{L}$ ), and free tetraiodothyronine (fT4) (normal range: 10.2-24.4 pmol/L) were measured using electrochemiluminescence immunoassay (E170, Mannheim, Germany).

\section{Statistical analysis}

Statistical analysis was done using the SPSS Statistics 20 software package (SPSS. Inc., Chicago, IL, USA). The results of the tests were usually expressed with numerical values, so the comparison between them was performed using a correlation with the Pearson Correlation test. To test hypotheses involving multiple samples, a standard Student t-test for two or more sam- 
ples was used. The Mann-Whitney U-test was used to test two independent samples. In the case of more than two samples, a Kruskal-Wallis $\mathrm{H}$ test of $\mathrm{K}$-independent samples was used, which is a one-way analysis of the variants of independent samples (one-way ANOVA on ranks). The level of statistical significance was set at $p$ value less than 0.05 .

\section{RESULTS}

Demographic data and pulmonary function tests of the study subjects are presented in Table 1. The two groups were similar regarding the gender and age distribution of the included subjects, as well as their smoking status, mean BMI, and height.

Diagnosis of an exacerbation relies on the clinical presentation of the patient complaining of worsening symptoms (dyspnea, cough, or sputum production) and leading to an increase in the use of maintenance medications and/or supplementation with additional medications that is beyond normal day-to-day variations [1]. This data was collected based on the medical history of each patient. Age, BMI, and height were not different between study groups.

The mean values of spirometry parameters (FVC, $\mathrm{FEV}_{1}$, and $\mathrm{FEV}_{1} / \mathrm{FVC}$ ratio) were significantly lower in COPD patients than in non-COPD controls $(p<0.0001)$.
Acute exacerbation frequency of IG was significantly higher than $C G(1.6 \pm 0.42$ and $0.82 \pm 0.79$ respectively; $\mathrm{p}<0.0001$ ).

According to the severity of airflow limitation, i.e. to the post-bronchodilator value of $\mathrm{FEV}_{1}$, COPD patients were categorized into four stages: mild (GOLD I), moderate (GOLD II), severe (GOLD III), and very severe COPD (GOLD IV) (Tab. 2).

Laboratory findings of thyroid function tests are presented in Table 3 . The number of patients with abnormal thyroid hormone status was significantly higher in stable COPD than control group $18(30 \%)$ vs $3(10.0 \%) ; p=0.0355 ; p<0.05$. Thyrotoxicosis with low serum TSH and higher serum level of fT3, according to the referent range, was present in 8 patients (13.3\%) and in none patient in the CG $0(0.0 \%) ; p=0.0375$; $p<0.05$. The prevalence of subclinical hyperthyroidism with low serum TSH and normal serum level of fT3 was higher in the IG - 10 patients (16.7\%) compared with $3(10.0 \%)$ in the CG, but the difference was not statistically significant $p=0.3970$.

The effect of thyroid function on COPD exacerbation frequency was examined. Only TSH was found to be significantly associated with acute exacerbation frequency. A positive significant relationship between acute exacerbation frequency and TSH values was found $(p<0.0001 ; r=0.82)$ (Fig. 1). The mean values of fT3 in the IG were significantly increasing with the increased severity of COPD. The degree of airflow limitation in COPD (FEV ${ }_{1}$ as a percentage of the predicted

Table 1. Demographic data and pulmonary function test

\begin{tabular}{|c|c|c|c|}
\hline Characteristic & $\begin{array}{l}\text { COPD patients } \\
(n=60)\end{array}$ & $\begin{array}{l}\text { Non-COPD subjects } \\
(\mathrm{n}=30)\end{array}$ & P-value \\
\hline $\begin{array}{l}\text { Gender } \\
\text { Males } \\
\text { Females }\end{array}$ & $\begin{array}{l}37(61.7 \%) \\
23(38.3 \%)\end{array}$ & $\begin{array}{l}21(70.0 \%) \\
9(30.0 \%)\end{array}$ & $p=0.4406$ \\
\hline $\begin{array}{l}\text { Mean age (years) } \\
\text { Male } \\
\text { Female }\end{array}$ & $\begin{array}{l}64.9 \pm 6.2 \\
65.9 \pm 5.4\end{array}$ & $\begin{array}{l}65.8 \pm 4.6 \\
64.7 \pm 5.2\end{array}$ & $\begin{array}{l}p=0.4837 \\
p=0.3172\end{array}$ \\
\hline $\begin{array}{l}\text { Smoking status } \\
\text { Active smokers } \\
\text { Former smokers } \\
\text { Pack-year smoked }\end{array}$ & $\begin{array}{l}35(58.3 \%) \\
25(41.7 \%) \\
66.1 \pm 25.8\end{array}$ & $\begin{array}{c}18(60 \%) \\
12(40 \%) \\
67.4 \pm 25.5\end{array}$ & $\begin{array}{l}p=0.8779 \\
p=0.8779 \\
p=0.8216\end{array}$ \\
\hline Mean BMI value $\left(\mathrm{kg} / \mathrm{m}^{2}\right)$ & $26.8 \pm 3.5$ & $27.1 \pm 3.2$ & $p=0.6944$ \\
\hline Height (cm) & $164.6 \pm 6.3$ & $166.4 \pm 6.9$ & $p=0.2191$ \\
\hline $\begin{array}{l}\text { Mean baseline values } \\
\text { of spirometry parameters } \\
\text { FVC (\% pred) } \\
\text { FEV }_{1}((\% \text { pred }) \\
\mathrm{FEV}_{1} / \mathrm{FVC} \text { ratio }\end{array}$ & $\begin{array}{c}75.8 \pm 10.3 \\
47.2 \pm 16.1 \\
0.6 \pm 0.05\end{array}$ & $\begin{array}{c}113.2 \pm 15.1 \\
91.2 \pm 13.9 \\
0.9 \pm 0.05\end{array}$ & $p<0.0001$ \\
\hline Acute exacerbation freq uency (/years) & $1.6 \pm 0.42$ & $0.82 \pm 0.79$ & $p<0.0001$ \\
\hline
\end{tabular}

$\mathrm{BMI}$ - body mass index; COPD — chronic obstructive pulmonary disease; FEV 1 — forced expiratory volume in one second; FVC — forced vital capacity; \%pred - percentage of the predicted value 
value, $\mathrm{FEV}_{1} \%$ pred) was significantly negatively correlated to fT3, Pearson correlation, $(R=-0.525 ; p=0.000$; $\mathrm{p}<0.01)$. $\mathrm{FEV}_{1} \%$ pred was positively correlated with TSH $(R=0.358 ; p=0.005 ; p<0.01)$.

Results of gas analyses in COPD and non-COPD subjects are presented in Table 4. Significant negative correlations were present between fT3 levels and both $\mathrm{PaO}_{2}$ and $\mathrm{O}_{2}$ saturation in the $\mathrm{IG}$ and elevation of $\mathrm{fT} 3$ was associated with higher $\mathrm{PaCO} 2$.

\section{Discussion}

COPD is a respiratory disease that is prevalent worldwide and has chronic airway inflammation as its major characteristic. In addition to airway inflammation, patients with COPD have inflammation in other body systems. It is not only a pulmonary disease but a systemic disease with numerous extrapulmonary manifestations. It is associated with many comorbidities that further increase hospital costs and reduce lifespan. The GOLD guidelines state that COPD is often complicated by many diseases, but thyroid dysfunction

Table 2. Distribution of the COPD patients by degree of airflow limitation

\begin{tabular}{|c|c|}
\hline COPD severity & $\begin{array}{l}\text { COPD patients } \\
(\mathrm{n}=60)\end{array}$ \\
\hline $\begin{array}{l}\text { GOLD } 1 \text { - mild } \\
\left(\text { FEV }_{1} \geq 80 \% \text { pred }\right)\end{array}$ & $4(6.7 \%)$ \\
\hline $\begin{array}{l}\text { GOLD } 2-\text { moderate } \\
\left(\mathrm{FEV}_{1}=50 \%-79 \% \text { pred }\right)\end{array}$ & 22 (36.7\%) \\
\hline $\begin{array}{l}\text { GOLD } 3 \text { - severe } \\
\left(\mathrm{FEV}_{1}=30 \%-49 \% \text { pred }\right)\end{array}$ & 21 (35.0\%) \\
\hline $\begin{array}{l}\text { GOLD } 4 \text { - very severe } \\
\left(\mathrm{FEV}_{1}<30 \% \text { pred }\right)\end{array}$ & $13(21.7 \%)$ \\
\hline
\end{tabular}

may be an underestimated complication of COPD due to insufficient clinical data $[1,19]$. In our study male patients dominated, which is probably due to the fact that men are main cigarette consumers, and smoking is the main risk factor. In the study $61.7 \%$ of participants were men, and $37.3 \%$ women, out of 60 COPD patients, current smokers constituted $58.3 \%$ and former smokers $41.7 \%$. The mean age of patients with COPD was for men $64.9 \pm 6.2$ and for women $65.9 \pm 5.4$. According to the GOLD criteria, they were predominantly in GOLD stage II and III on the basis of spirometry (FEV $\%$ pred 30-80\%). Our results presented a statistically significant difference between prevalence of thyroid hormones abnormalities in stable COPD compared to controls, 18 patients $(30.0 \%)$ vs $3(10.0 \%) ; p=0.0355 ; p<0.05)$. Previous studies showed that hypothyroidism was more common than hyperthyroidism in COPD patients, and its frequency showed positive correlation with the stage of COPD [20, 21].

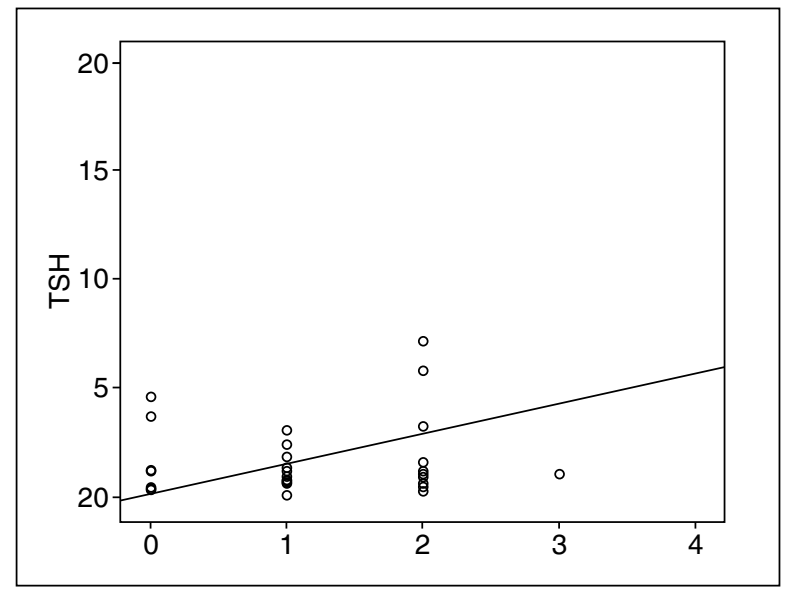

Figure 1. Relationship between thyroid TSH level and frequency of acute COPD exacerbation COPD - chronic obstructive pulmonary disease; TSH — thyroid stimulating hormone

Table 3. Presentation of thyroid hormone status in COPD and non-COPD subjects

\begin{tabular}{llll}
\hline Thyroid hormones & $\begin{array}{l}\text { COPD patients } \\
(\mathbf{n}=6 \mathbf{6})\end{array}$ & $\begin{array}{l}\text { Non-COPD subjects } \\
(\mathbf{n}=\mathbf{3 0})\end{array}$ & P-value \\
\hline Thyroid hormone status & & & \\
TSH $(\mathrm{mlU} / \mathrm{mL})$ & $4.7(0.3-18.89)$ & $0.7(0.4-4.5)$ & $\mathrm{p}<0.0001$ \\
fT4 (pmol/L) & $2.35 \pm 3.42$ & $2.47 \pm 3.32$ & $\mathrm{p}=0.8745$ \\
fT3 (pmol/L) & $3.37 \pm 1.21$ & $2.33 \pm 0.44$ & $\mathrm{p}<0.0001$ \\
Normal thyroid status & $42(70.0 \%)$ & $27(90.0 \%)$ & $\mathrm{p}=0.0355$ \\
Hyperthyroidism & $8(13.3 \%)$ & $3(10.0 \%)$ & $\mathrm{p}=0.6539$ \\
Subclinical hyperthyroidism & $10(16.7 \%)$ & $3(10.0 \%)$ & $\mathrm{p}=0.3970$ \\
\hline
\end{tabular}

COPD — chronic obstructive pulmonary disease; fT 4 - free tetraiodothyronine; fT3 — free triiodothyronine; TSH — thyroid stimulating hormone 
Table 4. Presentation of gas analyses in COPD and non-COPD subjects

\begin{tabular}{lccc}
\hline Gas analyses & $\begin{array}{c}\text { COPD patients } \\
(\mathbf{n}=\mathbf{6 0})\end{array}$ & $\begin{array}{c}\text { Non-COPD subjects } \\
(\mathbf{n}=\mathbf{3 0})\end{array}$ & P-value \\
\hline $\mathrm{PaO}_{2}(\mathrm{mmHg})$ & $48.41 \pm 9.9$ & $64.4 \pm 6.4$ & $\mathrm{p}<0.0001$ \\
$\mathrm{PaCO}_{2}(\mathrm{mmHg})$ & $41.1 \pm 10.8$ & $31.4 \pm 7.6$ & $\mathrm{p}<0.0001$ \\
$\mathrm{O}_{2}$ saturtion (\%) & $78.3 \pm 14.9$ & $88.1 \pm 4.2$ & $\mathrm{p}=0.0007$ \\
$\mathrm{pH}$ & $7.39 \pm 0.2$ & $7.45 \pm 0.4$ & $\mathrm{p}=0.3440$ \\
$\mathrm{HCO}_{3}(\mathrm{mmol} / \mathrm{L})$ & $27.2 \pm 5.9$ & $22.6 \pm 2.1$ & $\mathrm{p}=0.0001$ \\
\hline
\end{tabular}

COPD - chronic obstructive pulmonary disease; $\mathrm{HCO}_{3}$ : bicarbonate; $\mathrm{O}_{2}-$ oxygen; $\mathrm{PaCO}_{2}$ - partial pressure of carbon dioxide; $\mathrm{PaO}_{2}-$ partial pressure of oxygen; $\mathrm{pH}$ : potential of hydrogen

In our study hyperthyroidism was more frequent, serum level of TSH was lower than the normal range in 18 patients $(30.0 \%)$ of the IG and in $3(10.0 \%)$ in the $\mathrm{CG}$, with a statistically significant difference, $\mathrm{p}=0.0355$; $p<0.05$. Thyrotoxicosis with low serum TSH and higher serum level of fT3, according to the referent range, was present in 8 patients (13.3\%) and in none patient in the CG $0(0.0 \%) ; p=0.0375 ; p<0.05$. A cross-sectional study from Spain showed that patients with COPD had a higher prevalence of thyroid disease (14.2\%) than the expected standardized prevalence of chronic diseases $(11.06 \%)$, and the prevalence of thyroid disease was higher in female than male patients $(24.6 \%$ vs 10.9\%) [22]. The increase in TT3/TT4 and fT3 in COPD patients was previously reported in the study of Ulasli et al. [23]. El-Yazed et al. [24] demonstrated that the increase in fT3 showed a negative correlation with $\mathrm{PaO}_{2}$ and a positive correlation with $\mathrm{PaCO}_{2}$. The elevation of fT3 was associated with higher COPD severity. Bacakoglu et al. [25] demonstrated that low fT3 and fT4 levels increase the rates of invasive mechanical ventilation and mortality in patients with respiratory failure. Exacerbations of COPD are important events in the course of the disease, as exacerbations negatively affect the quality of life, accelerate the decline of pulmonary function and are associated with higher socioeconomic costs and mortality. Development of strategies to prevent exacerbations is an important goal in COPD management [1]. In our study, acute exacerbation frequency of IG was significantly higher than CG $(1.6 \pm 0.42$ and $0.82 \pm 0.79$ respectively; $\mathrm{p}<0.0001$ ). A positive significant relationship between acute exacerbation frequency and $\mathrm{TSH}$ values was found ( $p<0.0001 ; R=0.82)$. Both cigarette smoke and chronic inflammatory and COPD can impair the thyroid gland and lead to abnormal thyroid hormone production. Karadag et al. [11] demonstrated that the prevalence of non-thyroidal illness syndrome (abnormal thyroid hormone levels not due to thyroid disease) was $14-20 \%$ in patients with stable COPD and $70 \%$ in patients with acute exacerbation COPD.

\section{Conclusions}

This trial shows that thyroid abnormalities are not uncommon in COPD patients. The present study confirms that both clinical and subclinical hyperthyroidism was higher in patients with COPD, compared to the non-COPD group. A positive significant relationship between acute exacerbation frequency and TSH values was found. TSH and fT3 are related to lung function. A better understanding of the correlation between thyroid gland disorders and COPD may contribute to better care of patients.

The findings of the present study are subject to some limitations. First, only one center is included, and the relatively small size of the study subjects could have certain implications on the evaluated data and their interpretation. Second, the unequal distribution of COPD patients by degree of airflow limitation could have a certain influence on the data obtained and their interpretation.

\section{Conflict of interest: None.}

\section{Funding: None.}

\section{References}

1. Global Initiative for Chronic Obstructive Lung Disease (GOLD). Executive Summary: Global Strategy for Diagnosis, Management, and Prevention of COPD — Updated 2021. www. goldcopd.org (20.08.2021).

2. Budev MM, Arroliga AC, Wiedemann HP et al. Cor pulmonale: an overview. Semin Respir Crit Care Med. 2003; 24(3): 233-244, doi: 10.1055/s-2003-41105, indexed in Pubmed: 16088545.

3. Sabit R, Bolton CE, Fraser AG, et al. Sub-clinical left and right ventricular dysfunction in patients with COPD. Respir Med. 2010; 104(8): 1171-1178, doi: 10.1016/j.rmed.2010.01.020, indexed in Pubmed 20185285.

4. Sin DD, Man SF. Chronic obstructive pulmonary disease: a novel risk factor for cardiovascular disease. Can J Physiol Pharmacol. 2005; 83(1): 8-13, doi: 10.1139/y04-116, indexed in Pubmed: 15759045.

5. Anthony S, Fauci A, Braunwald E, Kasper D, Hauser S, Longo D, Jameson JL, Loscalzo J. Principles of Harrison's Internal Medicine. 17th Ed. McGraw-Hill Professional, New York 2008: 1635-1642. 
6. Miłkowska-Dymanowska J, Białas AJ, Zalewska-Janowska A, et al Underrecognized comorbidities of chronic obstructive pulmonary disease. Int J Chron Obstruct Pulmon Dis. 2015; 10: 1331-1341, doi 10.2147/COPD.S82420, indexed in Pubmed: 26203239.

7. Uzun K, Atalay H, Inal A. Thyroid hormon levels in patients with acute exacerbation of chronic obstructive pulmonary disease. Eur J Gen Med. 2007; 4(2): 80-82, doi: 10.29333/ejgm/82490.

8. Doehner W, Haeusler KG, Endres M, et al. Neurological and endocrinological disorders: orphans in chronic obstructive pulmonary disease. Respir Med. 2011; 105(Suppl 1): S12-S19, doi: 10.1016/S09546111(11)70005-1, indexed in Pubmed: 22015080.

9. Dimopoulou I, llias I, Mastorakos G, et al. Effects of severity of chronic obstructive pulmonary disease on thyroid function. Metabolism. 2001; 50(12): 1397-1401, doi: 10.1053/meta.2001.28157, indexed in Pubmed: 11735083

10. Różycka-Kosmalska M, Michalak R, Kosmalski M, et al. Clinical procedure in amiodarone-induced thyroid dysfunction [article in Polish]. Po Merkur Lekarski. 2016; 40(235): 46-52, indexed in Pubmed: 26891437.

11. Karadag F, Ozcan H, Karul AB, et al. Correlates of non-thyroidal illness syndrome in chronic obstructive pulmonary disease. Respir Med. 2007; 101(7): 1439-1446, doi: 10.1016/j.rmed.2007.01.016, indexed in Pubmed: 17346957.

12. Miłkowska-Dymanowska J, Białas AJ, Laskowska P, et al. Thyroid gland in chronic obstructive pulmonary disease. Adv Respir Med 2017: 85(1): 28-34, doi: 10.5603/ARM.2017.0006, indexed in Pubmed: 28198991

13. Meral I, Arslan A, Him A, et al. Smoking-related alterations in serum levels of thyroid hormones and insulin in female and male students. Altern Ther Health Med. 2015; 21(5): 24-29, indexed in Pubmed: 26393988

14. Saaresranta T, Polo O. Hormones and breathing. Chest. 2002; 122(6) 2165-2182, doi: 10.1378/chest.122.6.2165, indexed in Pubmed: 12475861

15. García-Olmos L, Alberquilla A, Ayala V, et al. Comorbidity in patients with chronic obstructive pulmonary disease in family practice: a cross sectional study. BMC Fam Pract. 2013; 14: 11, doi: 10.1186/1471-229614-11, indexed in Pubmed: 23324308
16. Gumus A, Ozyurt S, Ozcelik N, et al. Prevalence of non-thyroidal illness syndrome in COPD exacerbation and effect of hypoxaemia and hypercapnia on thyroid functions. Clin Respir J. 2020; 14(9): 806-812, doi: 10.1111/cri.13200, indexed in Pubmed: 32367619.

17. Stone IS, Barnes NC, Petersen SE. Chronic obstructive pulmonary disease: a modifiable risk factor for cardiovascular disease? Heart. 2012; 98(14): 1055-1062, doi: 10.1136/heartjnl-2012-301759, indexed in Pubmed: 22739636

18. Miller MR, Hankinson J, Brusasco V, et al. ATS/ERS Task Force. Standardisation of spirometry. Eur Respir J. 2005; 26(2): 319-338, doi: 10.1183/09031936.05.00034805, indexed in Pubmed: 16055882.

19. Huang D, Wu D, He J, et al. Association between thyroid function and acute exacerbation of chronic obstructive pulmonary disease. Int J Chron Obstruct Pulmon Dis. 2021; 16: 333-339, doi: 10.2147/COPD. S291807, indexed in Pubmed: 33628017.

20. Chaudhary SC, Ahmad T, Usman K, et al. Prevalence of thyroid dysfunction in chronic obstructive pulmonary disease patients in a tertiary care center in North India. J Family Med Prim Care. 2018; 7(3): 584-588, doi: 10.4103/jfmpc.jfmpc_84_17, indexed in Pubmed: 30112314.

21. Singh L, Jain A, Agrawal A, et al. study of prevalence of thyroid disorders in chronic obstructive pulmonary disease patients at a tertiary care center in U.P. Int J Contemp Med Res. 2016; 3(5): 1239-1242.

22. Akpınar EE. An underestimated comorbidity of COPD: thyroid dysfunction. Tuberk Toraks. 2019; 67(2): 131-135, doi: 10.5578/tt.68257, indexed in Pubmed: 31414644

23. Ulasli S, Bozbas S, Ozen Z, et al. Effect of thyroid function on COPD exacerbation frequency: a preliminary study. Multidis Res Med. 2013; 8(9), doi: 10.4081/mrm.2013.576

24. El-Yazed HA, El-Bassiony M, Eldaboosy S, et al. Assessment of thyroid functions in patients with chronic obstructive pulmonary disease. Egyptian Journal of Chest Diseases and Tuberculosis. 2013; 62(3): 387-391, doi: 10.1016/j.ejcdt.2013.07.009.

25. Bacakoğlu F, Başoğlu OK, Gürgün A, et al. Can impairments of thyroid function test affect prognosis in patients with respiratory failure? Tuberk Toraks. 2007; 55(4): 329-335, indexed in Pubmed: 18224499. 